\title{
GDF15 promotes osteosarcoma cell migration and invasion by regulating the TGF- $\beta$ signaling pathway
}

\author{
GUANGFU CHEN, MIN WANG and XIANG LIU \\ Department of Spine Surgery, The Affiliated Foshan Chancheng District Center Hospital \\ of Guangdong Medical University, Foshan, Guangdong 528031, P.R. China
}

Received August 14, 2018; Accepted March 25, 2019

DOI: $10.3892 / \mathrm{mmr} .2019 .10664$

\begin{abstract}
Growth and differentiation factor 15 (GDF15), a novel divergent member of the transforming growth factor- $\beta$ (TGF- $\beta$ ) superfamily, was previously reported to be overexpressed in various types of cancers and was shown to be involved in tumor metastasis; however, the role of GDF15 in the development and malignant progression of osteosarcoma remains unclear. In the present study, reverse transcription-quantitative polymerase chain reaction, western blot and ELISA analyses were performed to detect mRNA and protein expression, including that of GDF15, SMAD2 and SMAD3 Wound-healing and cell invasion assays were conducted to determine the migratory and invasive abilities of osteosarcoma cells. A luciferase assay was performed to evaluate the transcriptional activity of a TGF- $\beta / S M A D$-responsive luciferase reporter. The Kaplan-Meier method was used to generate survival curves, with a log-rank test use to evaluate differences in survival. The results revealed that GDF15 expression was upregulated in metastatic osteosarcoma tissues compared with non-metastatic osteosarcoma tissues. Patients with osteosarcoma that possessed high serum GDF15 levels exhibited significantly decreased overall survival (OS) and pulmonary metastasis-free survival (PMFS) time compared with patients with low GDF15 expression. Furthermore, high serum GDF15 was an independent prognostic parameter for poor OS and short PMFS. Additionally, it was observed that the knockdown of GDF15 attenuated the migration and invasion of osteosarcoma cells. Silencing GDF15 markedly suppressed the TGF- $\beta$ signaling pathway. In conclusion, GDF15 may promote osteosarcoma cell metastasis by regulating the TGF- $\beta$ signaling pathway, and serum GDF15 levels may be a potential
\end{abstract}

Correspondence to: Dr Guangfu Chen, Department of Spine Surgery, The Affiliated Foshan Chancheng District Center Hospital of Guangdong Medical University, 3 Sanyou South Road, Shiwan Town, Chancheng, Foshan, Guangdong 528031, P.R. China

E-mail: chen-guangfu@hotmail.com

Key words: growth and differentiation factor 15, osteosarcoma, pulmonary metastasis, transforming growth factor $-\beta$, prognosis prognostic and pulmonary metastasis-predictive biomarker in osteosarcoma.

\section{Introduction}

Osteosarcoma is the most common type of primary malignant tumor of the bone, particularly in children and adolescents (1), and exhibits a strong tendency for pulmonary metastasis $(2,3)$. Pulmonary metastasis is the main cause of failure in the treatment of patients with osteosarcoma $(4,5)$. Patients with pulmonary metastasis exhibit an increased rate of mortality compared with those without metastasis (5). The 5-year overall survival (OS) rate was $60-70 \%$ in patients with localized disease, but only $23 \%$ in patients with metastatic osteosarcoma $(4,6,7)$. Chou et al (8) reported that the addition of liposomal muramyl tripeptide phosphatidylethanolamine (MTP-PE) to conventional chemotherapy improved the event-free survival and OS of patients with metastatic osteosarcoma. Notably, the European Medical Agency has approved the use of MTP-PE for patients with osteosarcoma. The investigation of pulmonary metastasis may provide novel insight for the identification of appropriate treatment strategies. Thus, it would be of clear clinical significance to identify biomarkers of pulmonary metastasis or prognostic factors in patients with osteosarcoma.

Growth and differentiation factor 15 (GDF15) is a novel divergent member of the transforming growth factor- $\beta$ (TGF- $\beta$ ) superfamily, and has been reported to be involved in numerous physiological processes and cellular events, including metabolism, tissue differentiation and maintenance, apoptosis, angiogenesis, cell cycle arrest and tumor dissemination (9). Previous studies have identified GDF15 to be involved in various pathologies, including cancer, inflammation, cardiovascular diseases and dyserythropoietic diseases (10-12). Overexpression of GDF15 has been reported in numerous types of cancer and was associated with poor clinical outcomes $(11,13,14)$. Of note, there were significant increases in serum GDF15 levels reported following progression to carcinoma and metastasis in prostate, colon and endometrial cancer, suggesting that GDF15 may serve as an independent predictor of metastasis $(11,13,15)$; however, the role of GDF15 in osteosarcoma metastasis and its clinical relevance remain unclear. 
In the present study, it was observed that the expression of GDF15 was increased in metastatic osteosarcoma tissues. The upregulated expression of GDF15 was associated with poorer OS and reduced pulmonary metastasis-free survival (PMFS) compared with low GDF15 expression, and GDF15 was a significant prognostic factor in multivariate analysis. Furthermore, the downregulation of GDF15 effectively suppressed the migration and invasion of osteosarcoma cells. Additionally, it was revealed that the TGF- $\beta$ signaling pathway was involved in the GDF15-mediated metastasis of osteosarcoma cells. Increased serum GDF15 levels exhibited clear prognostic value for poor clinical outcome in osteosarcoma, and may serve as a promising biomarker for pulmonary metastasis, enabling the identification of high-risk patients and the selection of appropriate treatment strategies.

\section{Materials and methods}

Cell culture. The osteosarcoma cell lines U-2 OS, SaOS-2, 143B, MG-63 and HOS, and the human hFOB1.19 osteoblast and mouse NIH3T3 fibroblast cell lines, were purchased from the American Type Culture Collection, and cultured in Dulbecco's modified Eagle's medium (DMEM, Gibco; Thermo Fisher Scientific, Inc.) supplemented with $10 \%$ fetal bovine serum (HyClone; GE Healthcare Life Sciences) in a $37^{\circ} \mathrm{C}$ incubator containing 5\% $\mathrm{CO}_{2}$. MG-63 and U-2 OS cells were selected for subsequent experiments (transfection, migration and invasion assays, and luciferase assays) due to their increased GDF15 expression. For simulating extracellular secretion of GDF15, cells were treated with $50 \mathrm{ng} / \mathrm{ml}$ recombinant human GDF15 (rhGDF15; R\&D Systems, Inc.) at $37^{\circ} \mathrm{C}$ for $24 \mathrm{~h}$.

Patient information and tissue samples. The present study was approved by the Ethics Committee of the Affiliated Foshan Chancheng District Center Hospital of Guangdong Medical University according to the 1975 Declaration of Helsinki (ethics approval no. IRB-ATT-001-24). All clinical samples were collected from the Affiliated Foshan Chancheng District Center Hospital of Guangdong Medical University. Patient written informed consent forms were obtained prior to the use of clinical specimens for research purposes. In the present study, 106 serum samples and 10 fresh tissues were collected from 106 patients (67 males and 39 females, aged 12-58 years), diagnosed pathologically with osteosarcoma, between January 2005 and December 2009. All patients received standard neoadjuvant chemotherapy, followed by resection of the tumor and postoperative chemotherapy. Clinical follow-up information, including Enneking staging (a system for staging bone cancer) (16), overall survival and pulmonary metastasis-free survival time, was available for all patients enrolled in the study. All serum samples (67 non-metastatic and 39 pulmonary metastatic osteosarcoma samples) were collected from the peripheral blood of patients with osteosarcoma prior to systemic treatment. The serum was obtained from blood samples by centrifugation at $1,000 \mathrm{xg}$ for $10 \mathrm{~min}$ at $4^{\circ} \mathrm{C}$, and then stored at $-80^{\circ} \mathrm{C}$ and thawed prior to analyses. Fresh osteosarcoma samples for reverse transcription-quantitative PCR (RT-qPCR) and ELISA analyses, including 4 non-metastatic and 4 pulmonary metastatic osteosarcoma tissues, and 2 adjacent non-tumor soft tissues, were obtained from 10 of the 106 aforementioned patients with osteosarcoma at the time of surgical resection, and immediately frozen at $-80^{\circ} \mathrm{C}$ until further use. In the present study, 106 serum samples and 10 fresh tissues were collected between January 2005 and December 2009. All patients received standard neoadjuvant chemotherapy, followed by resection of the tumor and postoperative chemotherapy.

Total RNA extraction and RT-qPCR. Total RNA samples from osteosarcoma cell lines and fresh surgical osteosarcoma tissues were extracted using TRIzol ${ }^{\circledR}$ reagent (Thermo Fisher Scientific, Inc.) according to the manufacturer's protocols. The isolated RNA was pretreated with RNase-free DNase. Then, the mRNA levels of GDF15 were evaluated by RT-qPCR. Total RNA $(2 \mu \mathrm{g})$ from samples was reverse transcribed to cDNA using M-MLV Reverse Transcriptase (Promega Corporation) according to the manufacturer's protocols. Briefly, total RNA $(2 \mu \mathrm{g})$ was incubated with random primers, heated to $70^{\circ} \mathrm{C}$ for $5 \mathrm{~min}$ and then placed on ice. A mix containing $1 \mathrm{X}$ M-MLV reaction buffer, dNTPs (all $0.5 \mathrm{mM}$ ), Recombinant RNasin ${ }^{\circledR}$ Ribonuclease Inhibitor (25 U) and M-MLV reverse transcriptase (200 U; Promega Corporation) was added to each sample at $37^{\circ} \mathrm{C}$ for $1 \mathrm{~h}$. All samples, including cDNAs, gene-specific primers and SYBR-Green (Roche Applied Sciences) were heated to $95^{\circ} \mathrm{C}$ for 5 min and then amplified for 35 cycles consisting of $95^{\circ} \mathrm{C}$ for $30 \mathrm{sec}$, a $30 \mathrm{sec}$ annealing step at a primer-specific annealing temperature, and $72^{\circ} \mathrm{C}$ for $45 \mathrm{sec}$. All reactions were then incubated at $72^{\circ} \mathrm{C}$ for $7 \mathrm{~min}$ and cooled to $4^{\circ} \mathrm{C}$. qPCR analysis was performed on an ABI Prism 7500 Sequence Detection System (Applied Biosystems; Thermo Fisher Scientific, Inc.). The results were normalized to the expression of the housekeeping gene GAPDH. Relative expression levels were determined using the following formula: $2^{-[(\mathrm{Cq} \text { of gene)-(Cq of GAPDH)] }}$, where $\mathrm{Cq}$ represents the threshold cycle for each transcript (17). The oligonucleotide primers are listed in Table I.

ELISA. The concentrations of GDF15 in serum and cell culture medium samples were determined using ELISA kits (1:250; cat. no. DGD150; R\&D Systems, Inc.). ELISAs were conducted according to the manufacturer's instructions. Briefly, the supernatant was transferred to a well coated with GDF15 monoclonal antibody (cat. no. MAB957; R\&D Systems, Inc.) and immunosorbed using biotinylated polyclonal anti-human GDF15 antibody (1:1,000; cat. no. BAF940, R\&D Systems, Inc.) at room temperature for $1 \mathrm{~h}$. The color development was catalyzed by horseradish peroxidase, and the absorption was detected at $450 \mathrm{~nm}$. The protein concentration was determined by comparing the relative absorbance of each sample with the standards. Patients were assigned to high and low GDF15 expression groups based on the results of the ELISA. Patients with serum GDF15 concentrations $<1 \mathrm{ng} / \mathrm{ml}$ were assigned to the low expression group; patients with serum GDF15 concentrations $\geq 1 \mathrm{ng} / \mathrm{ml}$ were assigned to the high expression group.

Plasmids, virus constructs and retroviral infection of target cells. Short-hairpin RNA (shRNA) against GDF15 (sense sequence: 5'-CTATGATGACTTGTTAGCCAA-3') in a Plko.1-puro vector was commercially purchased (Sigma-Aldrich; Merck KGaA). Retroviruses containing pLKO.1-puro-GDF15-Ri or pLKO.1-puro-vector were generated by transfecting 293FT cells (Invitrogen; Thermo Fisher 
Table I. Reverse transcription-quantitative PCR primers.

\begin{tabular}{ll}
\hline Name & \multicolumn{1}{c}{ Sequence (5'-3') } \\
\hline GDF15-UP & CTCCAGATTCCGAGAGTTGC \\
GDF15-DOWN & AGAGATACGCAGGTGCAGGT \\
SNAI1-UP & TTTACCTTCCAGCAGCCCTA \\
SNAI1-DOWN & CCCACTGTCCTCATCTGACA \\
SNAI2-UP & TCGGACCCACACATTACCTT \\
SNAI2-DOWN & TTGGAGCAGTTTTGCACTG \\
IL11-UP & AGCCACCACCGTCCTTCCAAA \\
IL11-DOWN & CCTCCGTCCCCACCCCAACAT \\
MMP13-UP & TTAAGGAGCATGGCGACTTCT \\
MMP13-DOWN & CCCAGGAGGAAAAGCATGAG \\
TWIST1-UP & GCTCTTCTCCTCTGCCCCGG \\
TWIST1-DOWN & CATCTAGGTCTCCGGCCCTG \\
ZEB1-UP & ACCTCTTCACAGGTTGCTCCT \\
ZEB1-DOWN & AGTGCAGGAGCTGAGAGTCA \\
COL1A1-UP & CCTTTCTGCTCCTTTCTCCA \\
COL1A1-DOWN & AGCAACACAGTTACACAAGG \\
VEGFA-UP & ATGATTCTGCCCTCCTCCTT \\
VEGFA-DOWN & CCTTGCTGCTCTACCTCCAC \\
GAPDH-UP & GCACCGTCAAGGCTGAGAAC \\
GAPDH-DOWN & TGGTGAAGACGCCAGTGGA
\end{tabular}

GDF15, growth and differentiation factor 15; SNAI, snail family transcriptional repressor; IL11, interleukin 11; MMP13, matrix metallopeptidase 13; TWIST1, twist family bHLH transcription factor 1; ZEB1, zinc finger E-box binding homeobox 1; COL1A1, collagen type I $\alpha 1$ chain; VEGFA, vascular endothelial growth factor A.

Scientific, Inc.). Virus particles were then examined by spectrophotometry at $260 \mathrm{~nm}$ and the infectivity of adenovirus stocks was evaluated using an Adeno-X Rapid Titre kit (Clontech Laboratories, Inc.), which determines infectious replication in 293FT cells. The virus particle/infectious focus-forming units (IFU) ratio was then calculated. The virus stocks used in the paper were GDF15-Ri (IFU ratio 43). MG-63 or U-2 OS cells $\left(2 \times 10^{5}\right)$ were seeded and infected with $500 \mu \mathrm{l} /$ day retroviral particles for 3 days. The stable cell lines were identified following treatment with $0.5 \mu \mathrm{g} / \mathrm{ml}$ puromycin for 10 days. The (CAGAC) 12/pGL3 TGF- $\beta$ /SMAD-responsive luciferase reporter plasmid and control plasmids (Clontech Laboratories, Inc.) were used to quantitatively evaluate the transcriptional activity of TGF- $\beta$ signaling components. All transfection experiments were performed using the Lipofectamine ${ }^{\circledR} 3000$ reagent (Invitrogen; Thermo Fisher Scientific, Inc.) according to the manufacturer's protocols, and cells were collected $24 \mathrm{~h}$ later for subsequent experiments.

Western blot analysis. Nuclear fractions were prepared using the Nuclear Extraction kit (Active Motif, Inc.) according to the manufacturer's protocols. Western blotting was conducted according to a standard method, as previously described (18). Briefly, cells were lysed, and protein sample (20 $\mu \mathrm{g} / \mathrm{lane})$ was separated via $10 \%$ SDS-PAGE and transferred to PVDF membranes. Following blocking with 5\% (w/v) skim milk for
$1 \mathrm{~h}$ at room temperature, membranes were incubated overnight at $4^{\circ} \mathrm{C}$ with primary antibodies. Antibodies against phosphorylated (p)-mothers against decapentaplegic homolog (SMAD)-2 (1:1,000; cat. no. 3108), p-SMAD3 (1:1,000; cat. no. 9520), SMAD2 (1:1,000; cat. no. 5339), and SMAD3 (1:1,000; cat. no. 9513) were purchased from Cell Signaling Technology, Inc. The GDF15 monoclonal antibody (1:1,000; cat. no. MAB957) was purchased from R\&D Systems, Inc. Anti- $\alpha$-tubulin (1:2,000; cat. no. T6199, Sigma-Aldrich; Merck KGaA) and anti-P84 (1:1,000; cat. no. ab102684; Abcam) antibodies were used as loading controls. Then the membrane was incubated with a secondary antibody for $1 \mathrm{~h}$ at room temperature. The secondary antibodies, goat anti-rabbit immunoglobulin G (1:2,000; cat. no. 31460, Pierce; Thermo Fisher Scientific, Inc.), and goat anti-mouse immunoglobulin G (1:2,000; cat. no. 31430, Pierce; Thermo Fisher Scientific, Inc.), were used in this study. Protein bands were visualized using an enhanced chemiluminescence kit (EMD Millipore).

Wound-healing and cell invasion assays. Wound-healing and cell invasion assays were conducted as described previously (19) to determine the migratory and invasive abilities of osteosarcoma cells. For the wound healing assay, in brief, $2 \times 10^{5}$ cells were seeded in 6-well plates, and the cell layer at $\sim 90 \%$ confluence was wounded using a sterile tip. The extent of wound closure was evaluated using a light microscope (magnification, x100) following incubation at $37^{\circ} \mathrm{C}$ for $24 \mathrm{~h}$. For the invasion assay, in brief, $2 \times 10^{3}$ cells suspended in serum-free DMEM were seeded into the upper Transwell chambers coated with Matrigel, whereas DMEM with 20\% FBS was seeded into the lower chambers. Then, cells were incubated at $37^{\circ} \mathrm{C}$ for $24 \mathrm{~h}$. The cells were fixed at $4 \%$ paraformaldehyde for $20 \mathrm{~min}$ and stained with $1 \%$ crystal violet for $1 \mathrm{~min}$ (both at room temperature), and the number of cells that reached the lower membrane was counted using a light microscope (magnification, x200). All experiments were performed in triplicate.

Luciferase assay. Luciferase assays were conducted as described previously (20). Briefly, cells $\left(1 \times 10^{4}\right)$ were seeded in triplicate in 48 -well plates, and cultured at $37^{\circ} \mathrm{C}$ for $24 \mathrm{~h}$. Then, $100 \mathrm{ng}$ of (CAGAC) 12/pGL3 reporter luciferase plasmid or control luciferase plasmid, and 3 ng pRL-TK Renilla plasmid (Promega Corporation) were transfected into shRNA- or rhGDP15-treated cells using Lipofectamine ${ }^{\circledR} 3000$ (Thermo Fisher Scientific, Inc.) according to the manufacturer's protocols. The luciferase and Renilla signals were measured $24 \mathrm{~h}$ following transfection using a Dual Luciferase Reporter Assay kit (Promega Corporation) according to the manufacturer's protocols; luciferase activity was normalized to Renilla activity.

Public microarray analyses. The microarray gene expression profiles in GSE9508 (21) were downloaded from the Gene Expression Omnibus (GEO; https://www.ncbi.nlm.nih. gov/geo/). The datasets were analyzed for the expression of GDF15. Information on the clinical characteristics, including metastasis status, were obtained from the respective clinical information files.

Heatmap. Gene expression was graphed into heatmaps using $\mathrm{MeV}$ version 4.9 software (http://mev.tm4.org). The pseudocolours represent the intensity scale of fold change of GDF15-Ri 
A

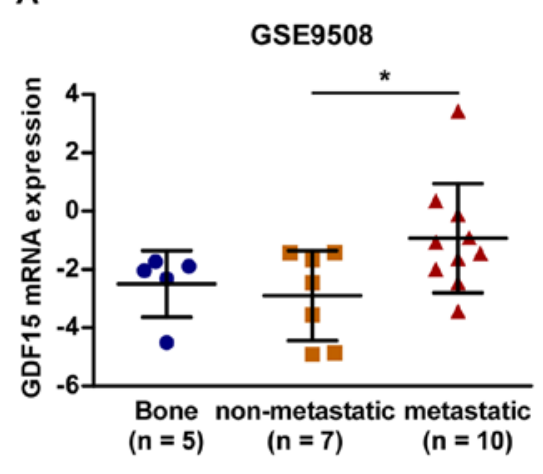

B

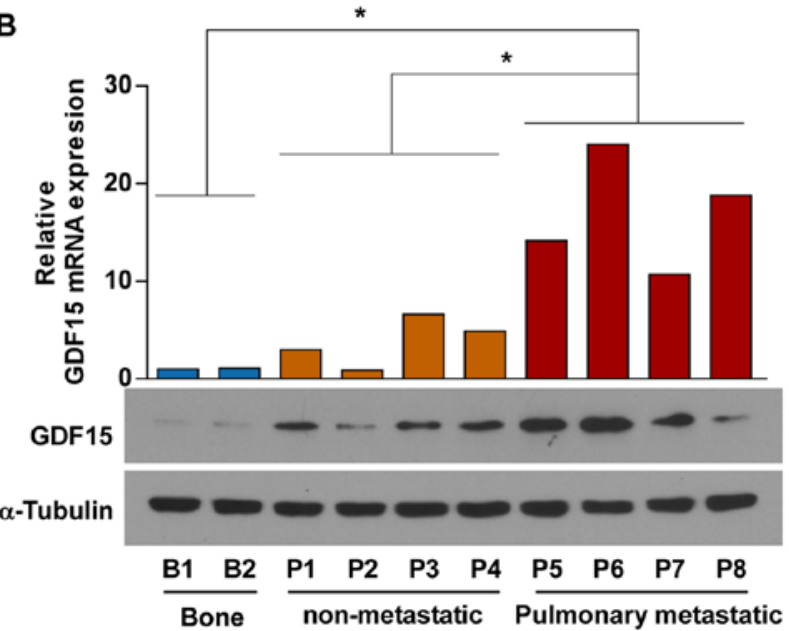

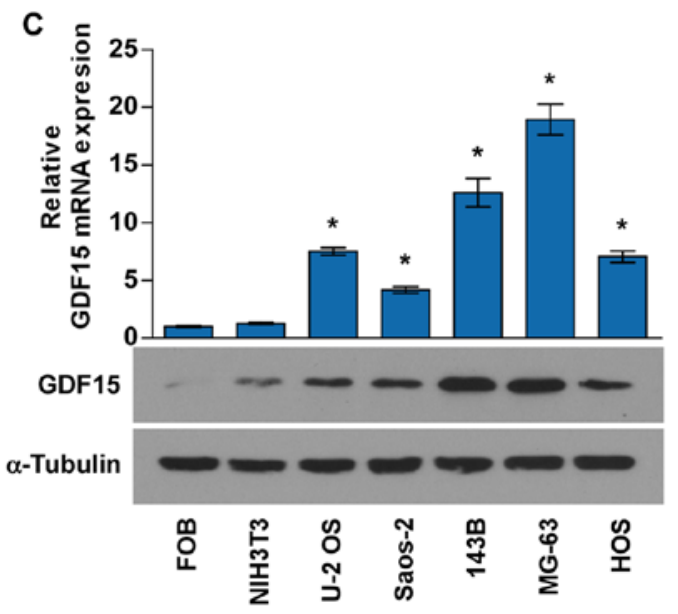

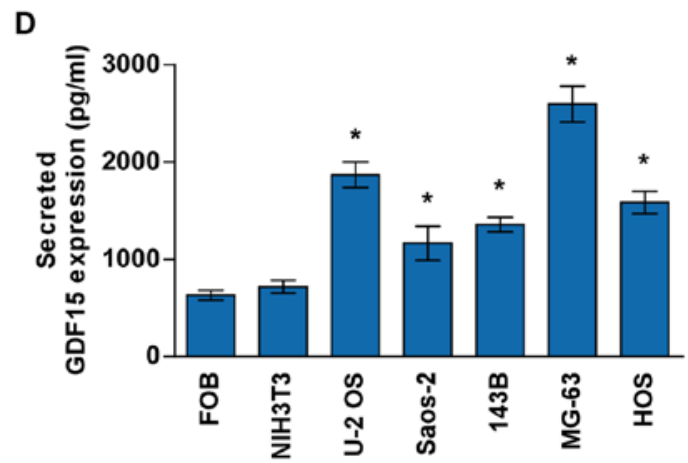

Figure 1. GDF15 is overexpressed in metastatic osteosarcoma tissues. (A) GDF15 mRNA expression levels were significantly upregulated in metastatic osteosarcoma compared with non-metastatic osteosarcoma samples in the GSE9508 dataset. " $\mathrm{P}<0.05$, as indicated. (B) GDF15 mRNA (upper panel) and protein (lower panel) expression levels in benign (B1-2), non-metastatic (P1-4) and pulmonary metastatic (P5-8) osteosarcoma tissue samples were determined via RT-qPCR and western blot analyses. "P $<0.05$, as indicated. (C) RT-qPCR (upper panel), western blot (lower panel) and (D) ELISA analyses of GDF15 expression in human osteosarcoma cell lines, human FOB osteoblasts and mouse NIH3T3 fibroblasts. ${ }^{*} \mathrm{P}<0.05$ vs. FOB. Data are presented as the mean \pm standard deviation of three independent experiments. GDF15, growth and differentiation factor 15; RT-qPCR, reverse transcription-quantitative polymerase chain reaction.

vs. vector, or GDF15-Ri + rhGDF15 vs. GDF15-Ri in MG-63 and U-2 OS, generated by $\log 2$ transformation.

Statistical analysis. All statistical analyses were conducted using SPSS version 17.0 software (SPSS, Inc.). Data are presented as the mean \pm standard deviation of three independent experiments. The associations between GDF15 protein expression and the clinicopathological characteristics of osteosarcoma patients were analyzed using $\chi^{2}$ tests. Survival curves were generated using the Kaplan-Meier method and survival was analyzed using the log-rank test. The significance of various variables for survival was analyzed to predict prognostic value using the Cox proportional hazards regression model in univariate and multivariate analyses. For the comparison of two groups, $\mathrm{P}$-values were calculated with a Student's t-test. One-way analysis of variance followed by a Newman-Keuls multiple comparison test was used to perform comparisons between multiple groups. $\mathrm{P}<0.05$ was considered to indicate a statistically significant difference.

\section{Results}

GDF15 is overexpressed in metastatic osteosarcoma tissues. GDF15 expression was first investigated in human osteosarcoma tissues by analyzing the GEO dataset GSE9508, containing gene expression profiles for metastatic and non-metastatic osteosarcoma biopsies. Notably, the mRNA levels of GDF15 were significantly increased in metastatic osteosarcoma tissues compared with in non-metastatic osteosarcoma tissues (Fig. 1A). Similar results were obtained when analyzing the mRNA and protein expression of GDF15 in 4 non-metastatic osteosarcoma tissues, 4 pulmonary metastatic osteosarcoma tissues and 2 adjacent non-tumor soft tissues (Fig. 1B). RT-qPCR, western blot and ELISA analyses were conducted to determine GDF15 mRNA and protein expression in five osteosarcoma cell lines (MG-63, HOS, U-2 OS, Saos-2 and 143B), human hFOB1.19 osteoblasts and mouse NIH3T3 fibroblasts. As presented in Fig. 1C and D, GDF15 was expressed at high levels in osteosarcoma cell lines compared with FOB and NIH3T3 cell lines.

High serum levels of GDF15 are associated with poor prognosis in patients with osteosarcoma. To further investigate the clinical relevance of serum GDF15 levels in patients with osteosarcoma, a total of 106 serum samples were examined for GDF15 expression by ELISA (Table II). $\chi^{2}$ tests revealed that high serum levels of GDF15 were significantly associated with vital status $(\mathrm{P}=0.010)$ and pulmonary metastasis $(\mathrm{P}<0.001)$ in 
Table II. Clinicopathological characteristics in 106 patients with osteosarcoma.

\begin{tabular}{lcr}
\hline Characteristics & Number of cases & $\%$ \\
\hline Sex & & \\
Female & 39 & 36.8 \\
Male & 67 & 63.2 \\
Age, years & & \\
$\leq 20$ & 77 & 72.6 \\
$21-40$ & 25 & 23.6 \\
$>40$ & 4 & 3.8 \\
Location & & \\
Distal femur & 60 & 56.6 \\
Proximal tibia & 24 & 22.6 \\
Proximal humerus & 11 & 10.4 \\
Proximal femur & 5 & 4.7 \\
Others & 6 & 5.7 \\
Enneking & & \\
IIB & 79 & 74.5 \\
III & 27 & 25.5 \\
Relapse & & \\
Yes & 8 & 7.5 \\
No & 98 & 92.5 \\
Pulmonary metastasis & & \\
Yes & 39 & 36.8 \\
No & 67 & 63.2 \\
Vital status (at follow-up) & & 57.5 \\
Alive & 61 & 42.5 \\
Deceased & 45 & \\
\hline & & \\
\end{tabular}

patients with osteosarcoma (Table III); however, there were no significant associations between GDF15 protein expression and other clinicopathologic characteristics.

Kaplan-Meier survival analysis and log-rank tests indicated that patients with osteosarcoma possessing high serum levels of GDF15 exhibited significantly poorer OS and reduced PMFS compared with those with low serum GDF15 levels (Fig. 2A and B). In addition, multivariate survival analyses revealed that serum GDF15 expression $(\mathrm{P}=0.004)$ was an independent prognostic factor for poor OS (Table IV), and that serum GDF15 expression $(\mathrm{P}<0.001)$ and Enneking stage $(\mathrm{P}=0.009)$ were independent prognostic factors for short PMFS (Table V). Thus, these results suggested that serum GDF15 may be a valuable prognostic marker in osteosarcoma.

GDF15 knockdown attenuates osteosarcoma cell migration and invasion. To explore the potential oncogenic functions of GDF15 in osteosarcoma cells, migration and invasion assays were performed. MG-63 and U-2 OS cells (selected for their high GDF15 expression) were transduced with lentiviruses carrying GDF15-shRNA or vector control, with downregulated expression demonstrated via RT-qPCR, western blot and ELISA analyses (Fig. 3A and B). As presented in Fig. 3C and D, GDF15-shRNA significantly suppressed the migration and
Table III. Association between GDF15 expression and clinicopathological characteristics of 106 patients with osteosarcoma.

\begin{tabular}{|c|c|c|c|}
\hline \multirow[b]{2}{*}{ Characteristics } & \multicolumn{2}{|c|}{$\begin{array}{c}\text { GDF15 } \\
\text { expression }\end{array}$} & \multirow[b]{2}{*}{ P-value } \\
\hline & Low & High & \\
\hline Sex & & & 0.218 \\
\hline Female & 29 & 10 & \\
\hline Male & 42 & 25 & \\
\hline Age, years & & & 0.893 \\
\hline$\leq 20$ & 52 & 25 & \\
\hline $21-40$ & 16 & 9 & \\
\hline$>40$ & 3 & 1 & \\
\hline Location & & & 0.464 \\
\hline Distal femur & 42 & 18 & \\
\hline Proximal tibia & 14 & 10 & \\
\hline Proximal humerus & 8 & 3 & \\
\hline Proximal femur & 2 & 3 & \\
\hline Others & 5 & 1 & \\
\hline Enneking & & & 0.323 \\
\hline IIB & 55 & 24 & \\
\hline III & 16 & 11 & \\
\hline Relapse & & & 0.231 \\
\hline Yes & 4 & 4 & \\
\hline No & 69 & 29 & \\
\hline Pulmonary metastasis & & & $<0.001$ \\
\hline Yes & 18 & 21 & \\
\hline No & 53 & 14 & \\
\hline Vital status (at follow-up) & & & 0.010 \\
\hline Alive & 47 & 14 & \\
\hline Deceased & 24 & 21 & \\
\hline
\end{tabular}

Low serum GDF15 level, Patients with serum GDF15 concentrations < $1 \mathrm{ng} / \mathrm{ml}$; High serum GDF15 level, Patients with serum GDF15 concentrations $\geq 1 \mathrm{ng} / \mathrm{ml}$; GDF15, growth and differentiation factor 15 .

invasion of MG-63 and U-2 OS osteosarcoma cells, whereas treatment with rhGDF15 rescued the migratory and invasive abilities of GDF15-silenced cells. Collectively, these results suggested that GDF15 knockdown inhibited the metastatic ability of osteosarcoma cells.

GDF15 knockdown suppresses the TGF- $\beta$ signaling pathway. GDF15 is a member of the TGF- $\beta$ superfamily (22), and TGF- $\beta$ signaling is an important pathway for maintaining metastatic phenotypes in osteosarcoma (23). Therefore, whether GDF15 promotes the migratory and invasive abilities of osteosarcoma cells via the activation of the TGF- $\beta$ signaling pathway was subsequently investigated. As presented in Fig. 4A-C, silencing GDF15 notably inhibited p-SMAD2/3 nuclear translocation, TGF- $\beta$ signaling activity and downstream target gene expression, whereas rhGDF15 reversed these effects in 
A

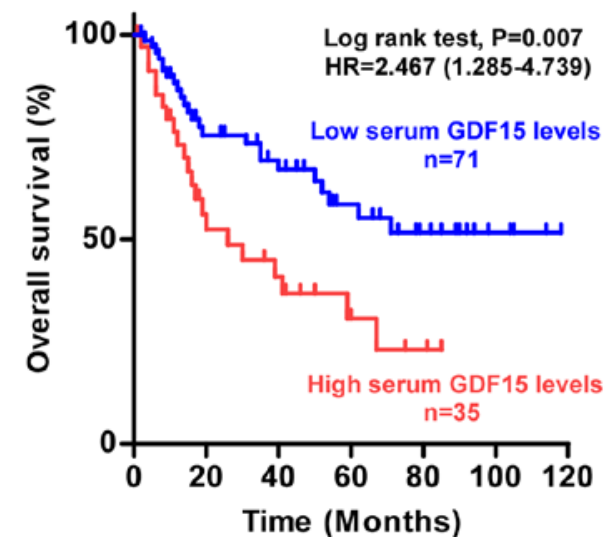

B

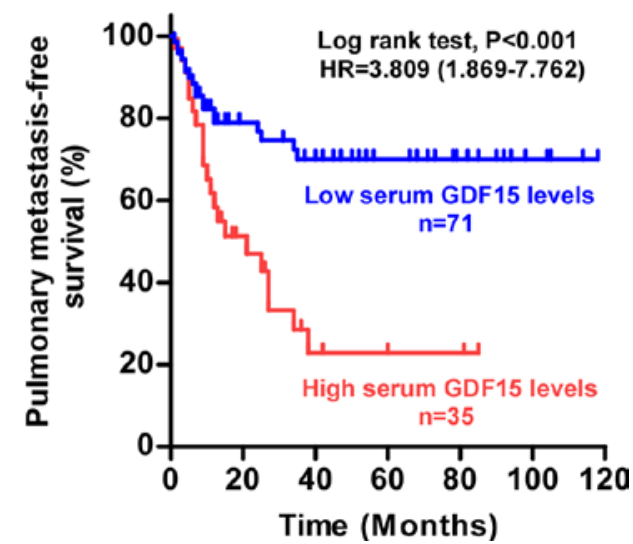

Figure 2. High serum levels of GDF15 are associated with poor clinical outcomes in patients with osteosarcoma. (A and B) Kaplan-Meier analysis of the (A) overall survival and (B) pulmonary metastasis-free survival of patients with osteosarcoma possessing high ( $\mathrm{n}=35$ ) or low GDF15 serum levels ( $\mathrm{n}=71$ ). P-values were determined using log-rank tests. Low serum GDF15 level: Patients with serum GDF15 concentrations <1 ng/ml. High serum GDF15 level: Patients with serum GDF15 concentrations $\geq 1 \mathrm{ng} / \mathrm{ml}$. GDF15, growth and differentiation factor 15; HR, hazard ratio.

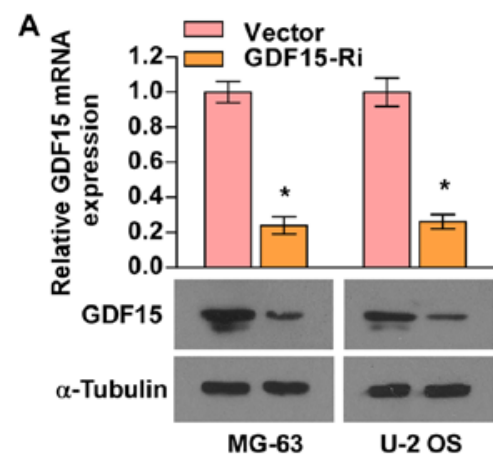

B

D

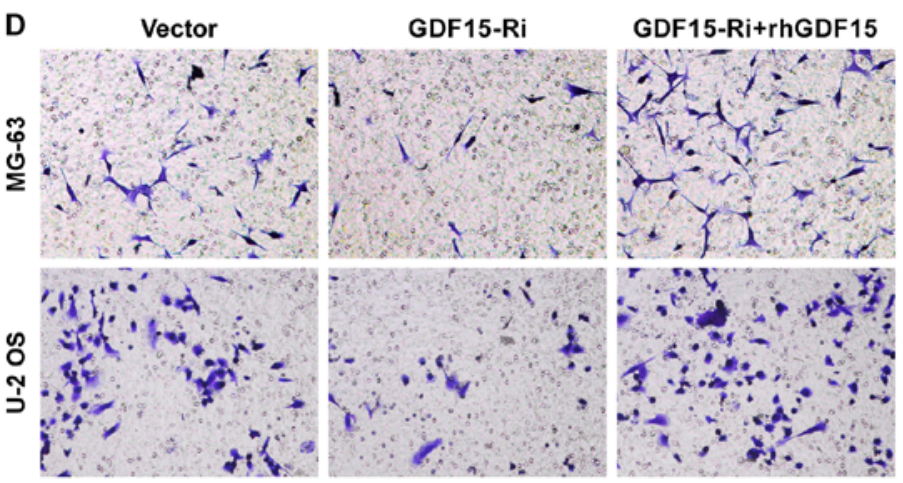

C
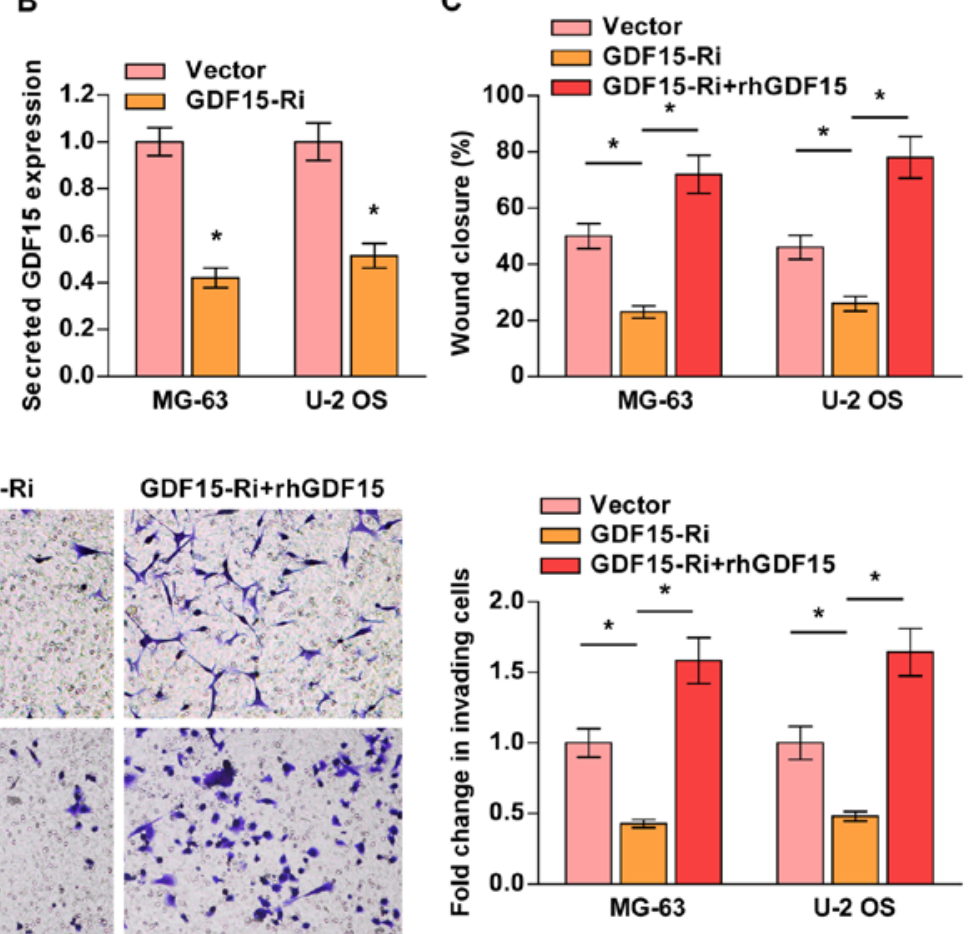

Figure 3. GDF15 knockdown attenuates the migration and invasion of osteosarcoma cells. (A) Reverse transcription-quantitative PCR (upper panel), western blot (lower panel) and (B) ELISA analyses of GDF15 expression in transduced MG-63 and U-2 OS cells. " $\mathrm{P}<0.05$ vs. Vector. (C) Quantification of wound-healing assays for the indicated cell lines after $24 \mathrm{~h} .{ }^{*} \mathrm{P}<0.05$ as indicated.(D) Representative micrographs (magnification, $\mathrm{x} 200$ ) and quantification of the invasive abilities of cells, as determined by Transwell invasion assays. Data are presented as the mean \pm standard deviation of three independent experiments. "P<0.05, as indicated. GDF15, growth and differentiation factor 15; GDF15-Ri, GDF15 shRNA treatment; Vector, vector control; rhGDF15, recombinant human GDF15.

GDF15-silenced cells. These findings indicated that GDF15 knockdown suppressed the TGF- $\beta$ signaling pathway, and that the TGF- $\beta$ signaling may be involved in the GDF15-induced metastasis of osteosarcoma cells (Fig. 4D).

\section{Discussion}

At the time of diagnosis, $18 \%$ of patients with osteosarcoma present with metastatic disease, with the most common $(81.2 \%)$ site being the lung $(2,24)$. The problem is even more serious, as $\sim 80 \%$ of patients with osteosarcoma are predicted to possess micrometastases, which are subclinical or undetectable using current diagnostic instruments (25). Furthermore, despite combined therapeutic modality, $40 \%$ of patients with localized osteosarcoma will experience treatment failure within 5 years following diagnosis and develop a local or distant relapse (4). It has been reported that $\sim 81.4 \%$ of relapses are pulmonary metastases, which usually occur within the first 2-3 years (4). At present, metastatic osteosarcoma is incurable and responsible for the majority of patient mortalities. Thus, there is an 
Table IV. Univariate and multivariate analysis of factors associated with overall survival in 106 patients with osteosarcoma.

\begin{tabular}{|c|c|c|c|c|c|c|}
\hline \multirow[b]{2}{*}{ Characteristics } & \multicolumn{3}{|c|}{ Univariate analysis } & \multicolumn{3}{|c|}{ Multivariate analysis } \\
\hline & HR & $95 \% \mathrm{CI}$ & P-value & HR & $95 \% \mathrm{CI}$ & P-value \\
\hline Age & 1.145 & $0.664-1.975$ & 0.627 & 0.907 & $0.515-1.600$ & 0.737 \\
\hline Sex & 0.850 & $0.459-1.573$ & 0.605 & 0.693 & $0.366-1.315$ & 0.262 \\
\hline Location & 0.789 & $0.598-1.040$ & 0.093 & 0.761 & $0.570-1.016$ & 0.064 \\
\hline Enneking stage & 0.926 & $0.446-1.926$ & 0.838 & 1.001 & $0.474-2.111$ & 0.999 \\
\hline GDF15 & 2.206 & $1.224-3.977$ & 0.008 & 2.474 & $1.345-4.550$ & 0.004 \\
\hline
\end{tabular}

CI, confidence interval; HR, hazard ratio; GDF15, growth and differentiation factor 15.

Table V. Univariate and multivariate analysis of factors associated with pulmonary metastasis survival in 106 osteosarcoma patients.

\begin{tabular}{|c|c|c|c|c|c|c|}
\hline \multirow[b]{2}{*}{ Characteristics } & \multicolumn{3}{|c|}{ Univariate analysis } & \multicolumn{3}{|c|}{ Multivariate analysis } \\
\hline & HR & $95 \%$ CI & P-value & HR & $95 \%$ CI & P-value \\
\hline Age & 1.102 & $0.623-1.948$ & 0.739 & 0.770 & $0.424-1.398$ & 0.391 \\
\hline Sex & 0.890 & $0.462-1.713$ & 0.727 & 0.727 & $0.371-1.426$ & 0.354 \\
\hline Location & 0.886 & $0.677-1.160$ & 0.378 & 0.837 & $0.632-1.108$ & 0.213 \\
\hline Enneking stage & 2.339 & $1.225-4.467$ & 0.010 & 2.436 & $1.250-4.747$ & 0.009 \\
\hline GDF15 & 3.077 & $1.630-5.808$ & 0.001 & 3.234 & $1.684-6.211$ & $<0.001$ \\
\hline
\end{tabular}

CI, confidence interval; HR, hazard ratio; GDF15, growth and differentiation factor 15.

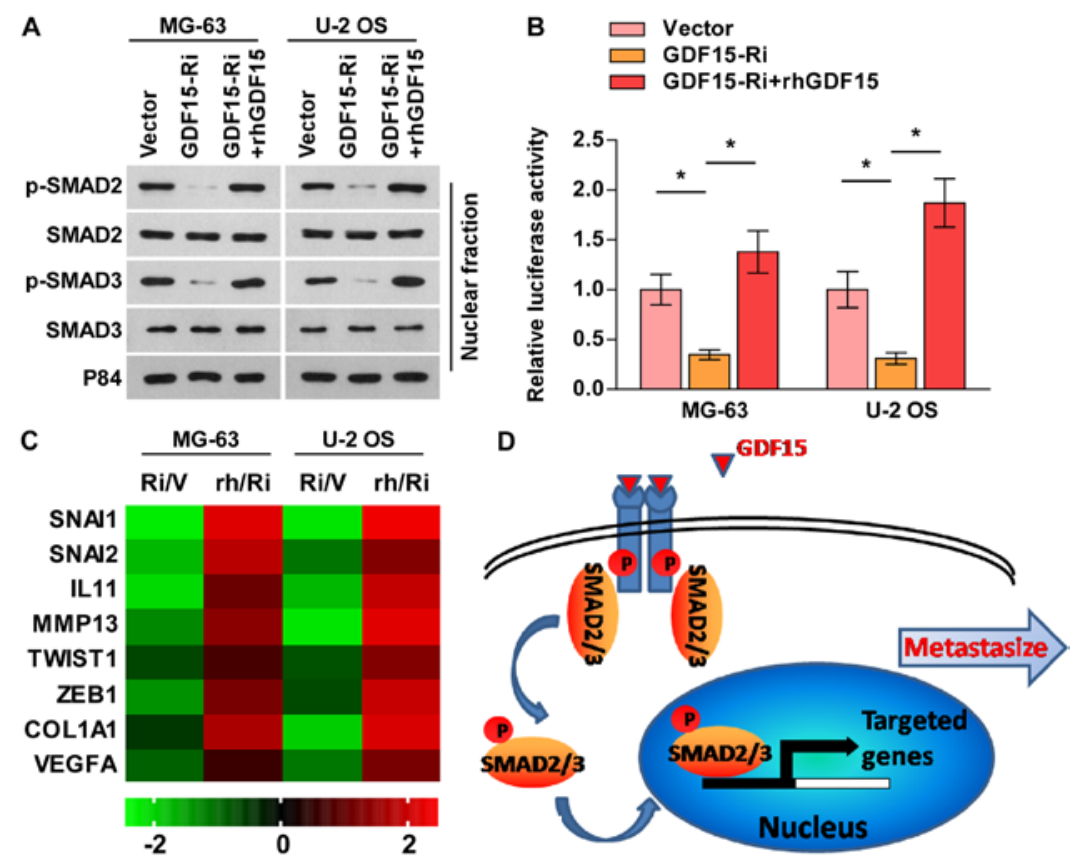

Figure 4. GDF15 knockdown suppresses the TGF- $\beta$ signaling pathway. (A) Nuclear p-SMAD2/3 expression as determined by western blot analysis. P84 was used as a loading control. (B) Transcriptional activity of a TGF- $\beta$ /SMAD-responsive luciferase reporter, as determined by a luciferase assay. (C) Fold-change in the mRNA expression of TGF- $\beta$ signaling-associated genes, as determined via reverse transcription-quantitative PCR analysis. (D) Schematic model. GDF15 activates the TGF- $\beta$ signaling pathway, leading to the metastasis of osteosarcoma. Data are presented as the mean \pm standard deviation of three independent experiments. "P<0.05, as indicated. GDF15, growth and differentiation factor 15; GDF15-Ri or Ri, GDF15 shRNA treatment; Vector/V, vector control; rhGDF15/rh, recombinant human GDF15; TGF- $\beta$, transforming growth factor- $\beta$; $\mathrm{p}-$, phosphorylated; SNAI, snail family transcriptional repressor; IL11, interleukin 11; MMP13, matrix metallopeptidase 13; TWIST1, twist family bHLH transcription factor 1; ZEB1, zinc finger E-box binding homeobox 1; COL1A1, collagen type I $\alpha 1$ chain; VEGFA, vascular endothelial growth factor A. 
urgent requirement for the improved understanding of the molecular mechanisms underlying the regulation of osteosarcoma pulmonary metastasis, and for a promising diagnostic and prognostic biomarker for metastatic osteosarcoma.

An increasing body of evidence has indicated that GDF15 is overexpressed in prostate, thyroid, pancreatic, and colonic cancers, and may possess potential clinical use in the diagnosis and/or monitoring of the progression of these diseases $(11,15,26)$. Brown et al (11) reported that GDF15 is an independent predictor of metastasis and overall survival in colorectal carcinoma. Similar results were obtained in prostate cancer and uveal melanoma $(15,27)$; however, its clinical relevance in osteosarcoma is yet to be determined. In the present study, it was reported that the expression of GDF15 was upregulated in pulmonary metastatic osteosarcoma tissues compared with non-metastatic osteosarcoma tissues and adjacent non-tumor soft tissues. Furthermore, it was demonstrated that the serum levels of GDF15 were increased in patients with metastatic osteosarcoma compared with those with non-metastatic osteosarcoma. High serum levels of GDF15 predicted poor OS and short PMFS. Thus, these results suggested that GDF15 may be useful for evaluating the prognosis of patients, and aid in the early diagnosis of pulmonary metastasis, which may support follow-up therapy in the future.

The effects of GDF15 on tumors appear to be contradictory, as GDF15 has been described as an antitumorigenic gene in previous studies. Li et al (28) first reported that GDF15 overexpression reduced MDA-MB-468 breast cancer cell viability by inducing G1 cell cycle arrest and apoptosis. GDF15-transfected HCT-116 cells exhibited increased basal apoptosis, reduced soft agar cloning efficiency and decreased tumorigenicity in athymic nude mice (29). Similarly, ectopic expression of GDF15 completely abolished the tumorigenicity of glioblastoma cells in nude mice (30). Conversely, emerging evidence has indicated that GDF15 also facilitated the migratory and invasive abilities of tumor cells. Lee et al (31) reported that GDF15 promoted the malignant progression of gastric cancer by inducing tumor cell invasion via the upregulation of urokinase-type plasminogen activator (uPA) and uPA receptor expression. In prostate cancer, recombinant GDF15 treatment reduced tumor cell adhesion and consequently accelerated tumor cell dissemination by downregulating Rho family GTPase 3 and catenin $\delta 1$ (32). These apparently contradictory effects of GDF15 may be due to tumor heterogeneity and the tumor environment, but this remains unclear. In the present study, it was observed that silencing GDF15 significantly suppressed the migratory and invasive abilities of osteosarcoma cell lines, whereas rhGDF15 rescued these effects in GDF15-silenced cells. Furthermore, GDF15 knockdown suppressed the TGF- $\beta$ signaling pathway. These findings suggested that GDF15 contributed to the progression of osteosarcoma and pulmonary metastasis, and that the TGF- $\beta$ signaling pathway may be involved in the GDF15-induced metastasis in osteosarcoma cells; however, the detailed molecular mechanisms require further investigation.

In conclusion, it was revealed that GDF15 was upregulated in pulmonary metastatic osteosarcoma tissues and patients' serum, and significantly associated with progression and prognosis in osteosarcoma. GDF15 is an important regulator of the TGF- $\beta$ signaling pathway and may promote osteosarcoma metastasis. Therefore, serum GDF15 may be a potential biomarker for pulmonary metastasis in osteosarcoma, enabling the identification of patients at high risk and informing the selection of appropriate therapeutic strategies.

\section{Acknowledgements}

Not applicable.

\section{Funding}

No funding was received.

\section{Availability of data and materials}

All data generated and analyzed during the present study are included in this published article.

\section{Authors' contributions}

GC and XL conceived and designed the current study. MW and XL performed the experiments. GC was responsible for data collection and analysis, and wrote the manuscript. All authors read and approved the manuscript.

\section{Ethics approval and consent to participate}

Written informed consent was obtained from all patients, and ethical approval was granted by the Ethics Committee of The Affiliated Foshan Chancheng District Center Hospital of Guangdong Medical University (Guangdong, China).

\section{Patient consent for publication}

Not applicable.

\section{Competing interests}

The authors declare that they have no competing interests.

\section{References}

1. Mirabello L, Troisi RJ and Savage SA: Osteosarcoma incidence and survival rates from 1973 to 2004: Data from the surveillance, epidemiology, and end results program. Cancer 115: 1531-1543, 2009.

2. Marko TA, Diessner BJ and Spector LG: Prevalence of metastasis at diagnosis of osteosarcoma: An international comparison. Pediatr Blood Cancer 63: 1006-1011, 2016.

3. Duchman KR, Gao Y and Miller BJ: Prognostic factors for survival in patients with high-grade osteosarcoma using the Surveillance, Epidemiology, and End Results (SEER) Program database. Cancer Epidemiol 39: 593-599, 2015.

4. Kempf-Bielack B, Bielack SS, Jürgens H, Branscheid D, Berdel WE, Exner GU, Göbel U, Helmke K, Jundt G, Kabisch H, et al: Osteosarcoma relapse after combined modality therapy: An analysis of unselected patients in the Cooperative Osteosarcoma Study Group (COSS). J Clin Oncol 23: 559-568, 2005.

5. Wu PK, Chen WM, Chen CF, Lee OK, Haung CK and Chen TH: Primary osteogenic sarcoma with pulmonary metastasis: Clinical results and prognostic factors in 91 patients. Jpn J Clin Oncol 39: 514-522, 2009. 
6. Goorin AM, Schwartzentruber DJ, Devidas M, Gebhardt MC Ayala AG, Harris MB, Helman LJ, Grier HE and Link MP: Presurgical chemotherapy compared with immediate surgery and adjuvant chemotherapy for nonmetastatic osteosarcoma: Pediatric oncology group study POG-8651. J Clin Oncol 21: 1574-1580, 2003.

7. Meyers PA, Heller G, Healey J, Huvos A, Lane J, Marcove R, Applewhite A, Vlamis V and Rosen G: Chemotherapy for nonmetastatic osteogenic sarcoma: The Memorial Sloan-Kettering experience. J Clin Oncol 10: 5-15, 1992.

8. Chou AJ, Kleinerman ES, Krailo MD, Chen Z, Betcher DL, Healey JH, Conrad EU III, Nieder ML, Weiner MA, Wells RJ, et al: Addition of muramyl tripeptide to chemotherapy for patients with newly diagnosed metastatic osteosarcoma: A report from the Children's Oncology Group. Cancer 115: 5339-5348, 2009.

9. Bauskin AR, Brown DA, Kuffner T, Johnen H, Luo XW, Hunter M and Breit SN: Role of macrophage inhibitory cytokine-1 in tumorigenesis and diagnosis of cancer. Cancer Res 66: 4983-4986, 2006.

10. Brown DA, Breit SN, Buring J, Fairlie WD, Bauskin AR, Liu T and Ridker PM: Concentration in plasma of macrophage inhibitory cytokine-1 and risk of cardiovascular events in women: A nested case-control study. Lancet 359: 2159-2163, 2002.

11. Brown DA, Ward RL, Buckhaults P, Liu T, Romans KE, Hawkins NJ, Bauskin AR, Kinzler KW, Vogelstein B and Breit SN: MIC-1 serum level and genotype: Associations with progress and prognosis of colorectal carcinoma. Clin Cancer Res 9: 2642-2650, 2003.

12. Tamary H, Shalev H, Perez-Avraham G, Zoldan M, Levi I, Swinkels DW, Tanno T and Miller JL: Elevated growth differentiation factor 15 expression in patients with congenital dyserythropoietic anemia type I. Blood 112: 5241-5244, 2008.

13. Staff AC, Trovik J, Eriksson AG, Wik E, Wollert KC, Kempf T and Salvesen HB: Elevated plasma growth differentiation factor-15 correlates with lymph node metastases and poor survival in endometrial cancer. Clin Cancer Res 17: 4825-4833, 2011.

14. Blanco-Calvo M, Tarrío N, Reboredo M, Haz-Conde M, García J, Quindós M, Figueroa A, Antón-Aparicio L, Calvo L and Valladares-Ayerbes M: Circulating levels of GDF15, MMP7 and $\mathrm{miR}-200 \mathrm{c}$ as a poor prognostic signature in gastric cancer. Future Oncol 10: 1187-1202, 2014.

15. Winand FJ, Boegemann M, Gallitz I, Hertle L, Semjonow A, Eveslage M, Van Aken HK, Herrmann E and Steinbicker AU: GDF15 and Hepcidin as prognostic factors in patients with prostate cancer. J Mol Biomark Diagn 5: 199, 2014.

16. Enneking WF, Spanier SS and Goodman MA: A system for the surgical staging of musculoskeletal sarcoma. Clin Orthop Relat Res: $106-120,1980$

17. Livak KJ and Schmittgen TD: Analysis of relative gene expression data using real-time quantitative PCR and the 2(-Delta Delta C(T)) method. Methods 25: 402-408, 2001.

18. Wang X, Ling MT, Guan XY, Tsao SW, Cheung HW, Lee DT and Wong YC: Identification of a novel function of TWIST, a bHLH protein, in the development of acquired taxol resistance in human cancer cells. Oncogene 23: 474-482, 2004.

19. Kong KL, Kwong DL, Fu L, Chan TH, Chen L, Liu H, Li Y, Zhu YH, Bi J, Qin YR, et al: Characterization of a candidate tumor suppressor gene uroplakin $1 \mathrm{~A}$ in esophageal squamous cell carcinoma. Cancer Res 70: 8832-8841, 2010.
20. Li Q, Ye L, Guo W, Wang M, Huang S and Peng X: PHF21B overexpression promotes cancer stem cell-like traits in prostate cancer cells by activating the Wnt/ $\beta$-catenin signaling pathway. J Exp Clin Cancer Res 36: 85, 2017.

21. Endo-Munoz L, Cumming A, Rickwood D, Wilson D, Cueva C, $\mathrm{Ng} \mathrm{C}$, Strutton G, Cassady AI, Evdokiou A, Sommerville S, et al: Loss of osteoclasts contributes to development of osteosarcoma pulmonary metastases. Cancer Res 70: 7063-7072, 2010.

22. Böttner M, Suter-Crazzolara C, Schober A and Unsicker K: Expression of a novel member of the TGF-beta superfamily, growth/differentiation factor-15/macrophage-inhibiting cytokine-1 (GDF-15/MIC-1) in adult rat tissues. Cell Tissue Res 297: 103-110, 1999.

23. Sung JY, Park SY, Kim JH, Kang HG, Yoon JH, Na YS, Kim YN and Park BK: Interferon consensus sequence-binding protein (ICSBP) promotes epithelial-to-mesenchymal transition (EMT)-like phenomena, cell-motility, and invasion via TGF- $\beta$ signaling in U2OS cells. Cell Death Dis 5: e1224, 2014.

24. Kager L, Zoubek A, Pötschger U, Kastner U, Flege S, Kempf-Bielack B, Branscheid D, Kotz R, Salzer-Kuntschik M, Winkelmann W, et al: Primary metastatic osteosarcoma: Presentation and outcome of patients treated on neoadjuvant Cooperative Osteosarcoma Study Group protocols. J Clin Oncol 21: 2011-2018, 2003.

25. Geller DS and Gorlick R: Osteosarcoma: A review of diagnosis, management, and treatment strategies. Clin Adv Hematol Oncol 8: 705-718, 2010.

26. Koopmann J, Buckhaults P, Brown DA, Zahurak ML, Sato N, Fukushima N, Sokoll LJ, Chan DW, Yeo CJ, Hruban RH, et al: Serum macrophage inhibitory cytokine 1 as a marker of pancreatic and other periampullary cancers. Clin Cancer Res 10: 2386-2392, 2004.

27. Suesskind D, Schatz A, Schnichels S, Coupland SE, Lake SL, Wissinger B, Bartz-Schmidt KU and Henke-Fahle S: GDF-15: A novel serum marker for metastases in uveal melanoma patients. Graefes Arch Clin Exp Ophthalmol 250: 887-895, 2012.

28. Li PX, Wong J, Ayed A, Ngo D, Brade AM, Arrowsmith C, Austin RC and Klamut HJ: Placental transforming growth factor-beta is a downstream mediator of the growth arrest and apoptotic response of tumor cells to DNA damage and p53 overexpression. J Biol Chem 275: 20127-20135, 2000.

29. Baek SJ, Kim KS, Nixon JB, Wilson LC and Eling TE: Cyclooxygenase inhibitors regulate the expression of a TGF-beta superfamily member that has proapoptotic and antitumorigenic activities. Mol Pharmacol 59: 901-908, 2001.

30. Albertoni M,Shaw PH,Nozaki M,Godard S, Tenan M,Hamou MF, Fairlie DW, Breit SN, Paralkar VM, de Tribolet N, et al: Anoxia induces macrophage inhibitory cytokine-1 (MIC-1) in glioblastoma cells independently of p53 and HIF-1. Oncogene 21: 4212-4219, 2002

31. Lee DH, Yang Y, Lee SJ, Kim KY, Koo TH, Shin SM, Song KS, Lee YH, Kim YJ, Lee JJ, et al: Macrophage inhibitory cytokine-1 induces the invasiveness of gastric cancer cells by up-regulating the urokinase-type plasminogen activator system. Cancer Res 63 : 4648-4655, 2003.

32. Liu T, Bauskin AR, Zaunders J, Brown DA, Pankhurst S, Russell PJ and Breit SN: Macrophage inhibitory cytokine 1 reduces cell adhesion and induces apoptosis in prostate cancer cells. Cancer Res 63: 5034-5040, 2003. 